\title{
Glucose Turnover and Disposal in Maturity-Onset Diabetes
}

\author{
H. F. Bowen and J. A. Moorhouse \\ From the Endocrine and Metabolism Laboratory, Winnipeg General Hospital \\ and the Departments of Physiology and Medicine, University of Manitoba, \\ Winnipeg, Manitoba, Canada, R3E OZ3
}

\begin{abstract}
A вSTRACT The glucose turnover rate in maturityonset diabetes in man has been variously reported as increased, normal, and decreased. The present experiments suggest that these discrepancies may have been due to methodology, and to nonrecognition of a circadian cycle in the glucose turnover rate that is present in health, and marked in diabetes.

During the early morning hours the glucose turnover rate in maturity-onset diabetes is increased in proportion to the fasting blood glucose level. It may reach three to four times the rate found in health. During the evening hours the increments are about one-half as great.

The glucose outflow rate constant, $k$, lower in diabetes than in health, is also lower in both groups in the evening than in the morning.

An analysis of the relative contributions of glucose overproduction and underutilization to the development of hyperglycemia in maturity-onset diabetes indicates that overproduction is the greater factor. The relative role of underutilization appears to increase as the fasting blood glucose level increases.

The circulating glucose oxidation rate in maturityonset diabetes is only slightly lower than in health, but the fraction oxidized is markedly lower, and only a small fraction is excreted.

The principal conclusion is that in maturity-onset diabetes there is a hypertrophied flux of endogenous glucose, most of which is neither oxidized nor excreted. The precursors and the qualitative and quantitative metabolic fates of this excess glucose are unknown.
\end{abstract}

\section{INTRODUCTION}

The endogenous glucose turnover rate in maturityonset diabetes in man is variously reported as decreased $(1,2)$, normal $(3-10)$ and increased $(11,12)$.

Received for publication 8 June 1972 and in revised form 13 August 1973.
We have examined aspects of methodology and of diurnal variability that appear to relate to this problem.

\section{METHODS}

Preliminary examination of tracer technics

Healthy subjects. Seven healthy subjects, aged 40-79, received $10 \mu \mathrm{Ci}$ of [U-C $\mathrm{C}^{14}$ ] glucose $\mathrm{e}^{1}$ as a single injection $(15,16)$ and as a primed constant infusion $(17,18)$ in varied sequence on separate days at 9:00 a.m. after a 14-h fast. Antecubetal venous blood samples were withdrawn at intervals for measurement of glucose level and radioactivity.

After the single injections, 12 blood samples were obtained over $4 \mathrm{~h}$. The fractional radioactivity disappearance rate was higher during the first than the last $2 \mathrm{~h}(k=0.81$ \pm SE $0.04 ; k=0.62 \pm$ SE $0.05, P<0.01$ ). Glucose turnover rates were calculated from pool size (isotope dilution) $\times k$.

The primed constant infusion method (18) is described below.

The results of these paired measurements are shown in Table I. The values for glucose turnover by the primed infusion technic are lower than those derived from the single injection technic, especially in comparison to values based upon the commonly used early portion of the decay curve. In these paired experiments they also exhibit a lower intersubject standard error. The judgment was reached that the primed infusion technic was more precise, and probably more accurate.

In other preliminary experiments, the glucose turnover rate was measured by a nonprimed constant [U-C $\mathrm{C}^{\mathbf{1 4}}$ ]glucose infusion, equilibrium specific activity being estimated by tangent analysis of the blood radioactivity. In some subjects this method gave a value very similar to that from a primed infusion; in others the value was substantially higher. Results of seven paired experiments were: primed infusion, $5.6 \pm \mathrm{SE} 0.2 \mathrm{~g} / \mathrm{h}$; unprimed infusion, 7.0 $\mathrm{SE} 0.5$ $\mathrm{g} / \mathrm{h}$. The conclusion was that prediction of the plateau value by this method is not dependable.

\footnotetext{
${ }^{1}$ The uniformly labeled isotope is not diluted by glucose formed in the liver by the recycling of glucose through lactate $(13,14)$. In this paper, the term "glucose turnover" refers to new, nonrecycled glucose derived from nonlabeled precursors.
} 
TABLE I

Comparison of Glucose Turnover Rates Obtained in Healthy Subjects by Single Injection and by Primed Constant Infusion

\begin{tabular}{|c|c|c|c|}
\hline \multirow[b]{2}{*}{ Subject } & \multicolumn{2}{|c|}{ Single injection } & \multirow{2}{*}{$\begin{array}{l}\text { Constant } \\
\text { infusion } \\
\text { with } \\
\text { primer } \\
\text { dose }\end{array}$} \\
\hline & $\begin{array}{c}\text { 1st half decay } \\
\text { curve }\end{array}$ & $\begin{array}{l}\text { 2nd half decay } \\
\text { curve }\end{array}$ & \\
\hline & \multicolumn{3}{|c|}{$g / h$} \\
\hline K. L. & 7.7 & 6.4 & 4.5 \\
\hline E. G. & 8.1 & 7.0 & 6.2 \\
\hline R. C. & 8.1 & 0.6 & 4.8 \\
\hline B. M. & 7.6 & 6.8 & 5.3 \\
\hline A. C. & 4.7 & 3.7 & 5.3 \\
\hline E. P. & 6.8 & 6.4 & 5.9 \\
\hline R. A. & 7.9 & 6.4 . & 5.2 \\
\hline \multicolumn{4}{|l|}{ Mean } \\
\hline$\pm \mathrm{SEM}$ & $7.3 \pm 0.5$ & $6.2 \pm 0.4$ & $5.2 \pm 0.2$ \\
\hline
\end{tabular}

\section{Difficulty in application of the primed infusion technic to maturity-onset diabetes}

Difficulty in estimating the circulating glucose turnover rate in diabetic subjects because of the inconstancy of their blood glucose level has previously been mentioned $(1,5,8)$. In the experiments preliminary to this study, it was observed that the glucose level in untreated maturity-onset diabetic subjects characteristically declined during the daytime hours after 9:00 a.m. (Fig. 1). The level did not stabilize with longer fasting, but rather by the next morning it rose to or toward its original value, and then declined throughout the second day (Fig. 1). Although these responses varied somewhat between subjects (Fig. 1), it became clear that a circadian blood glucose cycle exists in

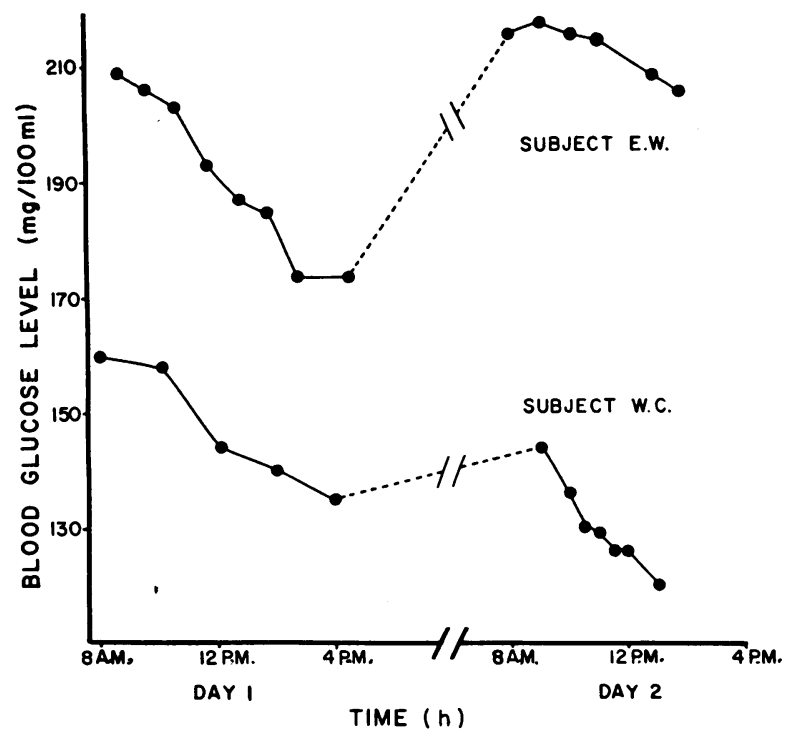

FIGURE 1 Blood glucose levels during a 42-h fast in two diabetic subjects. maturity diabetes. This was subsequently studied (19). The higher blood levels occur during the early morning and the lower levels during the early evening. It was decided that a satisfactory isotopic study of glucose turnover in diabetes could best be done at these times, when the blood glucose levels sufficiently approximate a steady state to allow an equilibrium specific activity to occur.

In all the studies now to be described, a primed infusion of $\left[\mathrm{U}-\mathrm{C}^{14}\right]$ glucose was administered between the hours of $6: 00$ and $9: 30 \mathrm{a} . \mathrm{m}$. on one day, and $6: 00$ and $9: 30 \mathrm{p} . \mathrm{m}$. on another day, in varied sequence.

Glucose turnover and oxidation by the primed infusion technic

A new group of 10 healthy persons and 10 patients with maturity-onset diabetes (Table II) was chosen. All were ambulatory and in good health apart from diabetes. Treatment was stopped. Usual diet was maintained until $6.5 \mathrm{~h}$ before the test $(11: 30$ a.m. or p.m. $)$, at which time the subject had a meat sandwich and a glass of milk, and then fasted. His habitual food-intake pattern was not otherwise disturbed, because blood glucose cyclicity is not dependent upon it (Fig. 1; 19), and because doing so might have induced an unstable adaptive period within the glucose control system. He arrived at the laboratory at $5: 30$ a.m. or p.m., voided, and lay down. An indwelling catheter was inserted into a forearm vein, and a blood sample obtained for blood glucose, plasma insulin, and plasma growth hormone estimations.

At 6:00, a priming dose (see Appendix) of [U-C $\left.{ }^{14}\right]$ glucose was injected, and a constant infusion lasting $3.5 \mathrm{~h}$ was started. Six venous blood samples were collected from a catheter in the opposite arm at equal intervals, beginning after $60 \mathrm{~min}$, for estimation of glucose level and radioactivity.

The point at which equilibrium specific activity was reacled was judged by inspection of the data. In health, all six specific activity values formed a plateau in 13 of the 20 studies, and in only one study was equilibration delayed until the last hour. In diabetes, specific activity equilibration occurred in the following numbers of samples counted from the end of the experiment: six in seven studies; five in one study; four in three studies; three in five studies; and two in three studies. In one diabetic subject equilibration did not occur, and asymptotic specific activity was calculated by tangent analysis. The stability of the equilibrium specific activities in the diabetic subjects was similar to that in health (mean percent variation about the estimated plateau $\pm \mathrm{SE}, 4.1 \pm 0.3$ vs. $3.9 \pm 0.4$, respectively).

Before each of the last two blood samples in nine healthy and seven diabetic subjects, a 10-min expired air sample was collected in a Douglas bag for estimation of $\mathrm{CO}_{2}$ content and radioactivity. Agreement between the values for $\mathrm{CO}_{2}$ specific activity in these samples was observed (43.6 \pm SE 3.5 vs. $45.2 \pm 3.7 \mathrm{cpm} / \mathrm{mg}$, respectively, $P>0.1$ ). Nevertheless, it is probable that equilibration within the body bicarbonate pool had not been reached $(20-23)$; if so, the amount of circulating glucose converted to $\mathrm{CO}_{2}$ during these experiments is underestimated.

At the end of the infusion, the subject provided a urine sample for estimation of glucose content.

The following equations were employed:

Glucose turnover rate $(\mathrm{g} / \mathrm{h})=$

$\left[\mathrm{U}-\mathrm{C}^{14}\right]$ glucose infusion rate $(\mathrm{cpm} / \mathrm{min}) \times 60$

glucose specific activity $(\mathrm{cpm} / \mathrm{mg}) \times 1000$ 
TABLE II

Characteristics of the Healthy and Diabetic Subjects

\begin{tabular}{|c|c|c|c|c|c|c|c|c|c|c|}
\hline \multirow{2}{*}{$\begin{array}{l}\text { Subject } \\
\text { No. }\end{array}$} & \multirow[b]{2}{*}{ Age } & \multirow[b]{2}{*}{ Sex } & \multirow[b]{2}{*}{ Height } & \multirow[b]{2}{*}{ Weight } & \multirow{2}{*}{$\frac{\text { Weight }}{\text { ideal wt. }}$} & \multirow{2}{*}{$\begin{array}{l}\text { Surface } \\
\text { area }\end{array}$} & \multicolumn{2}{|c|}{$\begin{array}{c}\text { Fasting blood } \\
\text { glucose level }\end{array}$} & \multicolumn{2}{|c|}{$\begin{array}{c}\text { Urinary glucose } \\
\text { loss }\end{array}$} \\
\hline & & & & & & & a.m. & p.m. & a.m. & p.m. \\
\hline \multicolumn{2}{|c|}{ Healthy subjects } & & in. & lbs. & $\%$ & $m^{2}$ & \multicolumn{2}{|c|}{$m g / 100 m l^{\circ}$} & \multicolumn{2}{|c|}{$g / h$} \\
\hline 1 & 40 & $\mathrm{~F}$ & 62 & 176 & 146 & 1.81 & 85 & 69 & - & - \\
\hline 2 & 46 & $\mathbf{M}$ & 68 & 156 & 105 & 1.83 & 79 & 79 & - & - \\
\hline 3 & 50 & $\mathrm{~F}$ & 67 & 176 & 112 & 1.91 & 78 & 75 & - & - \\
\hline 4 & 46 & M & 69 & 187 & 123 & 2.01 & 95 & 90 & - & - \\
\hline 5 & 66 & $\mathrm{~F}$ & 63 & 123 & 100 & 1.57 & 56 & 78 & - & - \\
\hline 6 & 61 & $\mathrm{~F}$ & 63 & 164 & 133 & 1.78 & 81 & 72 & - & - \\
\hline 7 & 82 & $\mathbf{M}$ & 67 & 151 & 105 & 1.80 & 72 & 77 & - & - \\
\hline 8 & 55 & $\mathrm{~F}$ & 58 & 132 & 123 & 1.72 & 75 & 101 & - & - \\
\hline 9 & 59 & $\mathrm{~F}$ & 65 & 161 & 122 & 1.86 & 92 & 83 & - & - \\
\hline 10 & 64 & $\mathrm{~F}$ & 59 & 142 & 129 & 1.58 & 87 & 91 & - & - \\
\hline \multicolumn{11}{|c|}{ Diabetic subjects } \\
\hline 1 & 70 & $\mathrm{~F}$ & 64 & 151 & 110 & 1.74 & 183 & 162 & 1.4 & 0.5 \\
\hline 2 & 61 & M & 63 & 144 & 112 & 1.75 & 175 & 154 & 0.5 & 0.2 \\
\hline 3 & 59 & $\mathrm{~F}$ & 64 & 153 & 120 & 1.73 & 278 & 200 & 6.6 & 1.0 \\
\hline 4 & 77 & M & 6.3 & 172 & 133 & 1.81 & 258 & 233 & 2.3 & 2.4 \\
\hline 5 & 60 & $\mathrm{~F}$ & 61 & 157 & 135 & 1.71 & 308 & 223 & 4.3 & 0.5 \\
\hline 6 & 74 & $\mathbf{M}$ & 62 & 175 & 138 & 1.82 & 287 & 257 & 0.9 & 2.6 \\
\hline 7 & 65 & M & 66 & 209 & 148 & 2.03 & 160 & 120 & - & - \\
\hline 8 & 61 & $\mathrm{~F}$ & 65 & 190 & 144 & 1.93 & 154 & 122 & - & - \\
\hline 9 & 57 & $\mathbf{M}$ & 65 & 146 & 107 & 1.74 & 154 & 123 & - & - \\
\hline 10 & 67 & $F$ & 66 & 209 & 155 & 2.03 & 186 & 138 & 1.9 & - \\
\hline
\end{tabular}

$\% \mathrm{CO}_{2}$ from glucose $=$

$\frac{\mathrm{CO}_{2} \text { specific activity }(\mathrm{cpm} / \mathrm{mg}) \times 44 \times 6 \times 100}{\text { glucose specific activity }(\mathrm{cpm} / \mathrm{mg}) \times 180}$

Amount of glucose to $\mathrm{CO}_{2}(\mathrm{~g} / \mathrm{h})=$

$\% \mathrm{CO}_{2}$ from glucose $\times \mathrm{CO}_{2}$ production rate $(\mathrm{g} / \mathrm{h}) \times 180$ $44 \times 6$

$\%$ glucose to $\mathrm{CO}_{2}=$

$$
\frac{\text { amount of glucose to } \mathrm{CO}_{2}(\mathrm{~g} / \mathrm{h}) \times 100}{\text { glucose turnover rate }(\mathrm{g} / \mathrm{h})}
$$

\section{Analytic methods}

Glucose. Radioactive glucose was isolated from $10 \mathrm{ml}$ of whole blood as [ $\mathrm{C}^{14}$ ]potassium gluconate $(24)$, and counted in a liquid scintillator (25). The recovery rate from whole blood was $33.1 \pm 0.7 \%$; its coefficient of variation was $7.6 \%$. Radioactivity in the infusate was determined by adding an aliquot to $10 \mathrm{ml}$ of preinfusion blood, and taking it through the above procedure. Blood glucose levels were determined by the Technicon ferricyanide method (Technicon Corporation, Ardsley, N. Y.).

Carbon dioxide. Expired air $\mathrm{CO}_{2}$ content was measured by infrared absorption (Model 16 Medical $\mathrm{CO}_{2}$ Analyzer, Liston-Becker Instrument Co., Stamford, Conn.). 2.0 liter of expired air was assayed for radioactive $\mathrm{CO}_{2}$ by the method of Fredrickson and Ono (26). Recovery rate, determined by the measurement of $\left[\mathrm{C}^{14}\right] \mathrm{CO}_{2}$ evolved from the quantitative potassium persulfate oxidation of [U-C $\left.{ }^{14}\right]$ glucose, was $100 \pm$ SD $2 \%$. Variation about the mean of duplicate analysis was $1.8 \pm \mathrm{SD} 1.2 \%$. The volume of the remaining expired air was determined by passage through a gas-flow meter (Model S-M-210, American Meter Controls, Philadelphia). All volumes were corrected to STP.

Insulin and growth hormones. Immunoassayable serum levels of insulin and growth hormone (standard courtesy of National Pituitary Agency, NIH, Baltimore) were determined by double-antibody technics based upon those of Morgan and Lazarow (27).

\section{RESULTS}

Glucose turnover in health and diabetes by the primed infusion technic. Fig. 2 shows the relationship of the glucose turnover rate to body surface area in the morning and in the evening in the 10 healthy subjects. The correlation coefficients are higher than those between turnover rate and percent ideal body weight (a.m.; $r=-0.36, P>0.3$; p.m.; $r=0.01, P>0.9$ ). This suggested that the relationship to body size is due to intersubject differences in lean body mass rather than to obesity. In any case, because of this relationship, the rates in all subjects were normalized to a surface area of $1.8 \mathrm{~m}^{2}$ by the equations in Fig. 2. A significant 


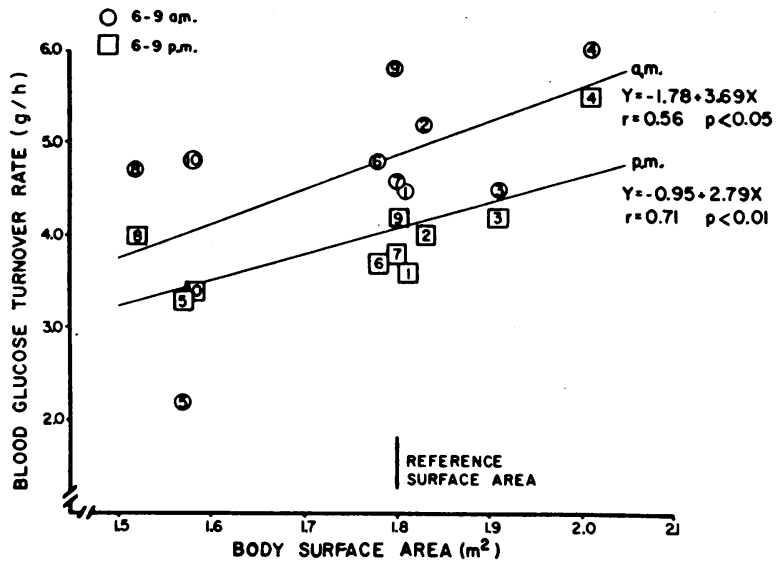

Figure 2 The relationship of the circulating glucose turnover rate to body surface area in the morning and in the evening in the 10 healthy subjects. The numbers identify the subjects (Table II). All data were subsequently normalized to a surface area of $1.8 \mathrm{~m}^{2}$, indicated by the vertical bar, according to the equations shown.

relationship of the glucose turnover rate to age was not present (a.m.; $r=-0.31, P>0.3 ;$ p.m.; $r=$ $-0.38, P>0.2)$ in this small group of subjects over age 40 .

Fig. 3 shows the relationship of the glucose turnover rate to the postabsorptive blood glucose level in the morning and in the evening in the healthy subjects. The rates range from 3 to $6 \mathrm{~g} / \mathrm{h} / 1.8 \mathrm{~m}^{2}$. They were significantly higher in the morning than in the evening $(t=3.27, P<0.005)$. At both times there is a significant correlation with the blood glucose level.

Fig. 4 shows the relationship of the glucose turnover rate to the postabsorptive blood glucose level in the morning and in the evening in the subjects with untreated maturity-onset diabetes. Note the difference in scales between this figure and Fig. 3. In the lower left corner are plotted the regression lines fitted to the data from the healthy subjects (Fig. 3), reduced to scale. The single circles, to which the long straight line is fitted, indicate the glucose turnover rates in the diabetic subjects in the morning. These values range between 8 and $18 \mathrm{~g} / \mathrm{h} / 1.8 \mathrm{~m}^{2}$. They show a marked and apparently linear correlation with the blood glucose level. The downward extrapolation of this regression nearly intersects the data from the healthy subjects. Six of the diabetic subjects were treated with two daily injections of lente insulin for 7-10 days, and retested in the morning. The results (double circles) fall close to the regression lines fitted to the data from the untreated diabetic subjects and from the healthy subjects. The squares are the data from the untreated diabetic subjects in the evening. As in the healthy subjects, these data are lower than those obtained in the morning $(t=4.35, P<0.001)$. and they form a different regression in relation to the prevailing blood glucose level. This regression appears to be curved, so that at lower blood glucose values the distinction between the two relationships is lost. The lines in the diagram are descriptive only of the appearance of the data; some aspects of their meaning are unclear. The degree of lessening of the evening glucose turnover rate in the diabetic subjects is variable, but sometimes very marked, especially in those with high blood glucose levels; the purpose of Table III is to make this point succinct.

Fig. 5 is similar to Fig. 4. The data in it were obtained by subtracting the rate of urine glucose loss (Table II) from the respective glucose turnover rate (Fig. 4 and Table III). The difference is the rate of tissue glucose uptake. Its relationships to the prevailing blood glucose level are qualitatively the same as those for the total glucose turnover rate in Fig. 4. Thus, urine glucose loss contributes in a quantitatively minor way to the glucose turnover-concentration relationship in maturity-onset diabetes, and does not determine its nature.

Pathogenesis of hyperglycemia in maturity-onset diabetes. In any pool-flow system, level is deternined by the rate of inflow and the resistance to outflow. The primed infusion technic measures the glucose inflow rate. Thus the elevation of the blood glucose level in maturity-onset diabetes results in part at least from an increased glucose inflow rate. Is the resistance to

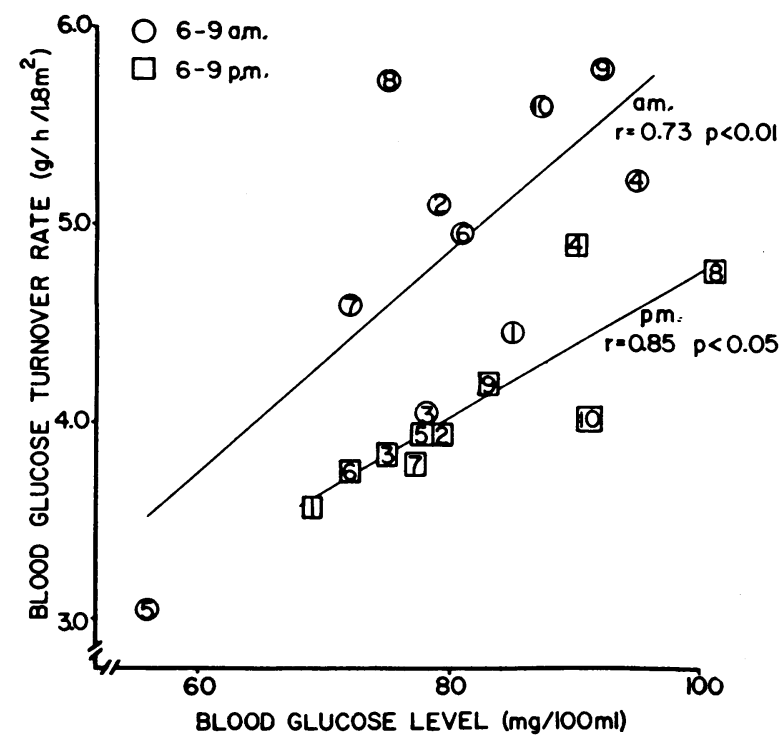

FIGURE 3 The relationship of the circulating glucose turnover rate to the fasting blood glucose level in the morning and in the evening in the healthy subjects. The blood glucose level has pragmatically been assigned to the $\mathrm{x}$-axis because it is the value commonly measured. 


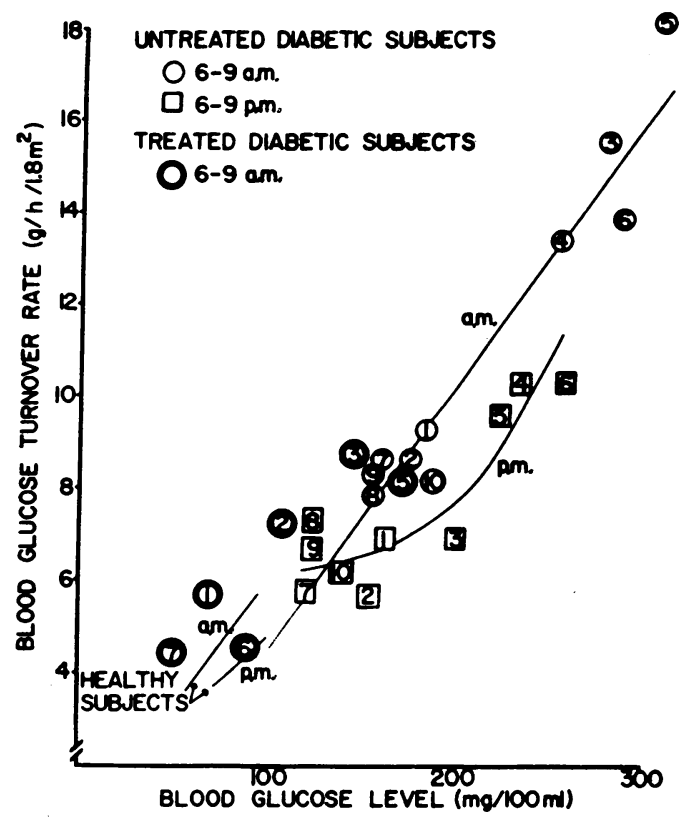

FIGURE 4 The relationship of the circulating glucose turnover rate to the fasting blood glucose level in the morning and in the evening in the subjects with maturity-onset diabetes. The regression lines from the heaithy subjects (Fig. 3) are entered at the lower left corner. The linear regression line was fitted by the least squares method to the morning data from the untreated diabetic subjects (single circles). Some of these subjects were subsequently treated with two daily doses of lente insulin and retested in the morning (double circles). The curved regression line was visually fitted to the evening data from the untreated diabetic subjects (squares). The numbers identify the subjects (Table II).

glucose outflow also increased, or does it remain the same as in health?

An expression of the resistance to glucose outflow is the coefficient $k$, which is the percent of the glucose pool removed per minute. The value of $k$ for each subject was derived as follows. The mean (i.e. morning and evening) glucose space was calculated (18) from the dilution of the primer dose of $\left[\mathrm{U}-\mathrm{C}^{14}\right]$ glucose (the variation of these duplicate estimates from their respective means was $3.5 \pm \mathrm{SD} 3.5 \%$ ). Then:

$$
k=\frac{I-U}{V \times R} \times 100
$$

where $I=$ the infusion rate of counts $(\mathrm{dpm} / \mathrm{min}), U$ $=$ the urinary loss of counts $(\mathrm{dpm} / \mathrm{min}) V=$ the glucose space (1) and $R=$ glucose radioactivity in plasma water (blood glucose radioactivity $\div 0.83$; dpm/liter) .

The relationship of $k$ to the fasting blood glucose level in the morning and in the evening in health and in maturity-onset diabetes is shown in Fig. 6. In accordance with the rate-concentration relationships in
TABLE III

Diurnal Variation in Glucose Turnover Rate in Maturity-Onset Diabeles

\begin{tabular}{|c|c|c|c|c|c|}
\hline \multirow{2}{*}{$\begin{array}{c}\text { Diabetic } \\
\text { Subject } \\
\text { No. }\end{array}$} & \multicolumn{2}{|c|}{ FBS } & \multicolumn{2}{|c|}{ Glucose turnover rate } & \multirow{2}{*}{$\frac{\text { Evening }}{\text { morning }} \times 100$} \\
\hline & a. $\mathrm{m}$. & p. $\mathrm{m}$. & Morning & Evening & \\
\hline & \multicolumn{2}{|c|}{$\mathrm{mg} / 100 \mathrm{ml}$} & \multicolumn{2}{|c|}{$\mathrm{g} / \mathrm{h} / 1.8 \mathrm{~m}^{2}$} & \\
\hline 8 & 154 & 122 & 8.0 & 7.2 & 90 \\
\hline 9 & 154 & 123 & 8.2 & 6.7 & 82 \\
\hline 7 & 160 & 120 & 8.7 & 5.8 & 67 \\
\hline 2 & 175 & 151 & 8.6 & 5.7 & 66 \\
\hline 1 & 183 & 162 & 9.2 & 6.9 & 75 \\
\hline 10 & 186 & 138 & 8.2 & 6.2 & 75 \\
\hline 4 & 253 & 243 & 13.4 & 10.2 & 76 \\
\hline 3 & 278 & 200 & 14.8 & 6.9 & 47 \\
\hline 6 & 287 & 266 & 13.8 & 10.2 & 74 \\
\hline 5 & 308 & 223 & 18.1 & 9.6 & 53 \\
\hline
\end{tabular}

The subjects are ranked according to their morning blood glucose level. FBS, fasting blood glucose level.

Fig. $5, k$ is less (i.e. resistance is greater) in the evening than in the morning in healthy subjects $(t=$ 2.91; $P<0.02)$, and in those diabetic subjects whose evening blood glucose level was greater than $150 \mathrm{mg} /$ $100 \mathrm{ml}(t=3.46 ; P<0.1)$; this change is appropriate to glucose level maintenance, as the glucose inflow declines toward evening. The $k$ values are generally less in the diabetic than in the healthy subjects, but overlap occurs. The data give the overall appearance of a curvilinear decline in $k$ as the blood glucose level increases. Treatment of diabetes with insulin tended to restore $k$ to within the normal range. The data indi-

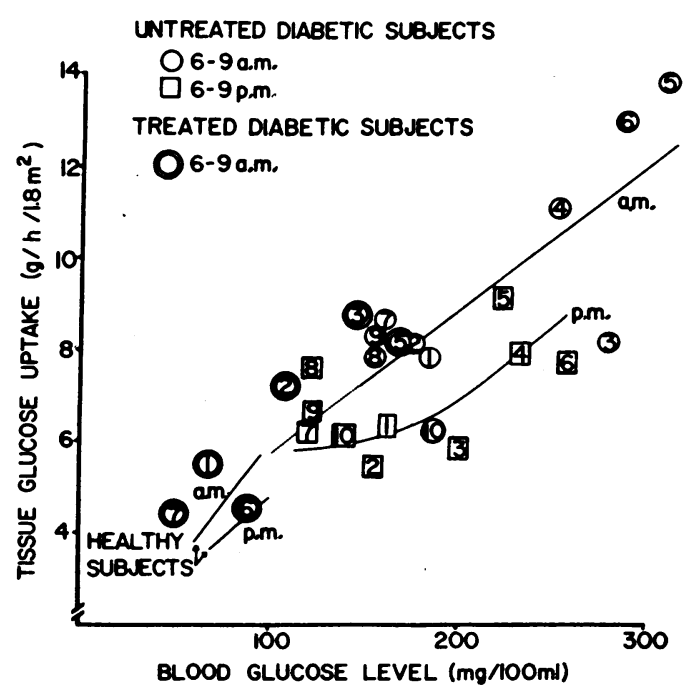

Figure 5 The relationship of the tissue glucose uptake rate (glucose turnover rate, Fig. 7 , Table III, minus urine glucose excretion rate, Table II) to the fasting blood glucose level in the morning and in the evening in the subjects with maturity-onset diabetes. The design of the figure is the same as that of Fig. 4. 
cate that the increase in the blood glucose level in maturity-onset diabetes is caused in part by an increase in the resistance to glucose outflow, as well as in the rate of glucose inflow.

Overproduction vs, underutilization. The conclusion that both the glucose inflow rate and outflow resistance are increased in maturity diabetes relates to the longstanding debate about the relative quantitative contributions of glucose overproduction and underutilization. Can it be resolved for this form of diabetes? The wide range of values both in the healthy and in the diabetic subjects for the glucose inflow rate and for $k$ suggests that these relative contributions are variable amongst individuals. In any case, the scatter of the data is such that they cannot be calculated for individuals in this cross-sectional study. Nevertheless, it appeared that one might visualize, from average values and relationships what happens to glucose kinetics in a hypothetic, reference man as he develops maturity-onset diabetes, and it proved interesting to do so. The rationale is as follows.

At equilibrium within the blood glucose control system there are four interrelated values: the blood glucose level, the glucose space, the rate of glucose inflow, and the glucose outflow rate constant. If three are known, the fourth can be calculated. Consider the blood glucose level. At equilibrium, the rate of glucose outflow is established by the rate of glucose inflow; the glucose pool size necessary to achieve that rate of glucose outflow is established by the glucose outflow

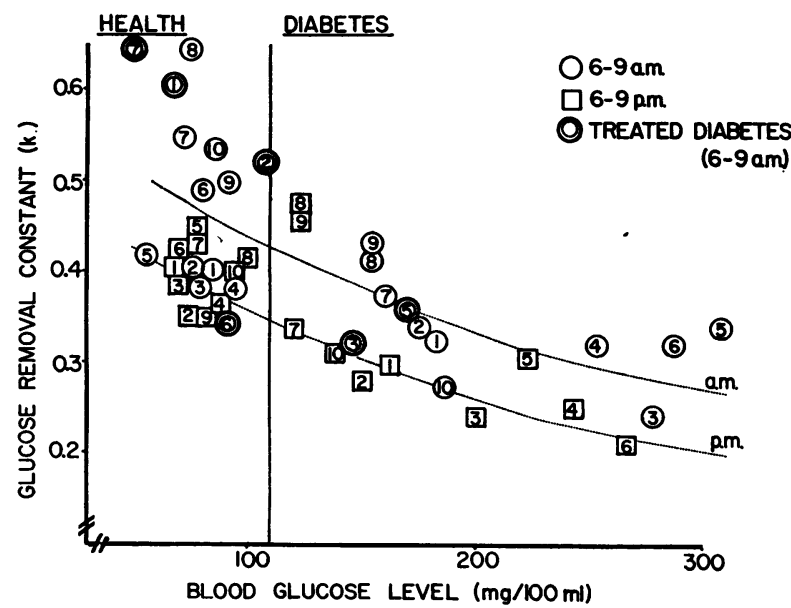

Figure 6 The relationship of the glucose outflow rate constant, $k$, to the fasting blood glucose level in the morning and in the evening in the healthy and in the maturityonset diabetic subjects. The curved regression lines were visually fitted to the morning and evening data. The points from the subjects subsequently treated with two daily doses of lente insulin, and retested in the morning, are indicated by the double circles. The numbers identify the subjects (Table II).
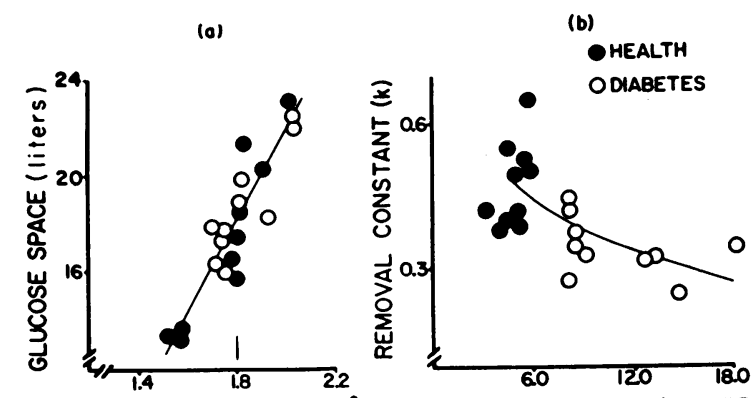

BOOY SURFACE AREA $\left(\mathrm{m}^{2}\right)$ GLUCOSE ENTRY RATE $\left(\mathrm{g} / \mathrm{h} / 18 \mathrm{~m}^{2}\right)$

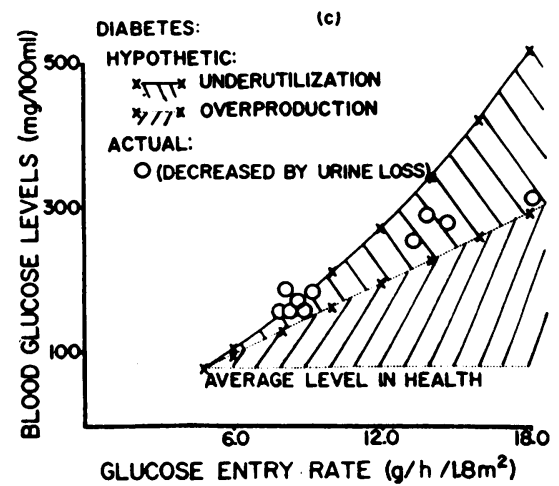

Figure 7 An hypothetic analysis of the relative contribution of glucose overproduction and underutilization to the development of hyperglycemia in a reference diabetic man having a surface area of $1.8 \mathrm{~m}^{2}$ and average values for glucose space, rate of inflow, and resistance to outflow. $a$. The relationship of the circulating-glucose space to body surface area. The intercept for $1.8 \mathrm{~m}^{2}$ is 18.1 liters. $b$. The relationship of the glucose outflow rate constant to the glucose entry rate. $c$. Hypothetic blood glucose levels $(X)$ in the reference diabetic subject, and actual blood glucose levels $(O)$ in the subjects of this study. The lower line indicates the average glucose level for healthy subjects. The middle line $(X-\cdots \times)$ indicates the hypothetic levels in the diabetic subject if the glucose entry rate alone had increased, and the value of $k$ had remained the same as in health. Thus the shaded area //// represents the component of hyperglycemia contributed by glucose overproduction. The upper line $(\times-X)$ indicates the hypothetic levels derived from the observed average changes of both $k$ and the glucose entry rate (panel $b$ ). Thus the shaded area $\backslash \backslash \backslash \backslash$ represents the component of hyperglycemia contributed by glucose underutilization. The circles show the actual blood glucose levels observed in the diabetic subjects. The difference between the circles and the upper line reflects the effect of urine glucose loss upon the blood glucose level; this loss from the glucose pool would not affect the proportional contributions to it of overproduction and underutilization. See text for further details.

rate constant; the blood glucose level required to provide that pool size is established by the glucose space. It follows that one can dissect out the two component causes of the rise in the blood glucose level in diabetes.

Consider a reference man having a surface area of $1.8 \mathrm{~m}^{2}$, and the average values for glucose space, rate 
TABLE IV

Glucose Oxidation in the Healthy and in the Diabetic Subjects

\begin{tabular}{llcl}
\hline & \multicolumn{1}{c}{$\begin{array}{c}\text { Healthy } \\
\text { subjects }\end{array}$} & $\begin{array}{c}\text { Diabetic } \\
\text { subjects }\end{array}$ & \\
\hline Body surface area, $m^{2}$ & $1.76 \pm 0.05$ & $1.83 \pm 0.04$ & \\
Total $\mathrm{CO}_{2}$ production, $g / h$ & a.m. $17.8 \pm 1.0$ & $20.1 \pm 0.8$ & \\
& p.m. $18.5 \pm 1.1$ & $21.0 \pm 1.2$ & \\
Amount of circulating & a.m. $2.8 \pm 0.3$ & $2.5 \pm 0.2$ & \\
glucose to $\mathrm{CO}_{2}, g / h^{*}$ & p.m. $2.6 \pm 0.3$ & $2.2 \pm 0.2$ & \\
Percent of circulating & a.m. $64 \pm 7$ & $24 \pm 3$ & $P<0.001$ \\
glucose to $\mathrm{CO}_{2} *$ & p.m. $64 \pm 8$ & $28 \pm 4$ & $P<0.01$ \\
& & $P<0.05$ & \\
Percent of $\mathrm{CO}_{2}$ from & a.m. $21.0 \pm 2.0$ & $18.3 \pm 1.4$ & \\
circulating glucose* & p.m. $20.6 \pm 1.3$ & $15.6 \pm 1.0$ & $P<0.01$ \\
& & $P<0.02$ & \\
\hline
\end{tabular}

Values are means \pm SEM. $P$ values are derived by paired or unpaired Student $t$ tests; only those which indicate statistical significance are shown. * The amounts shown are underestimates (see Discussion).

of inflow, and resistance to outflow seen in this study, and refer to Fig. 7. His glucose space, determined from the regression of space on surface area (Fig. 7a), is 18.1 liters. Before his diabetes, his glucose inflow rate is $4.9 \mathrm{~g} / \mathrm{h}$, and his glucose outflow rate constant is 0.47 (Fig. $7 b$ ). From these three values, his fasting blood glucose level (FBS) of $79 \mathrm{mg} / 100 \mathrm{ml}$ (bottom line, Fig. 7c) can be calculated by the equation:

$$
\mathrm{FBS}=\frac{O \times 0.83}{S \times 0.01 k}
$$

where $\mathrm{O}=$ the glucose outflow rate (which is equal to the glucose inflow) in $\mathrm{g} / \mathrm{min}, 0.83=$ the ratio of water to solids in whole blood, and $S=$ the glucose space in decaliters.

Next, suppose that as this reference man becomes diabetic, his glucose inflow rate rises, but his glucose outflow rate constant does not change. Then according to the above equation, the middle line in Fig. $7 c$ would result. Thus the lower shaded portion of Fig. $7 c$ represents the fraction of the increment of the blood glucose level attributable to excess glucose production as the reference man develops maturity-onset diabetes of increasing severity. Finally, the top line in Fig. $7 c$ is derived by substituting for the average normal value for $k$ in the equation, the average value which actually occurred in the subjects with maturity-onset diabetes of varying severity (Fig. $7 b$ ). Thus the upper shaded portion of Fig. $7 c$ represents the fraction of the increment of the blood glucose level attributable to his tendency to glucose underutilization as the reference man develops increasingly severe maturity-onset diabetes. The actual blood glucose values (open circles) are lower than those shown by the top line because of glycosuria; the urine glucose loss will, however, be derived from the two fractions in the same proportion as their con- tribution to the hypertrophy of the glucose pool. Accordingly to this overall analysis, underutilization tends to be somewhat the smaller of the two fractions, but tends to increase toward equality as the degree of diabetes increases.

Serum insulin and growth hormone levels. Fig. 8 shows the relationship of the serum immunoreactive insulin level to the fasting blood glucose level in the morning and in the evening in the healthy subjects and in the diabetic subjects who had not previously received insulin. There is no correlation at either time between these levels in health or in diabetes, nor is there a significant difference between the serum insulin levels found in the morning and in the evening. There is thus no evidence from this study that the relationship of the glucose turnover rate either to the blood glucose level or to the time of day is mediated by alterations in the serum insulin level. The possibility of a change in the portal serum insulin level not perceptible in peripheral serum is not excluded.

Serum immunoreactive growth hormone levels were measured in each subject. In both health and diabetes they ranged between 0.1 and $3.0 \mathrm{ng} / \mathrm{ml}$. The levels were not different in health and diabetes, and they showed no relationship to either the blood glucose level or the time of day.

Glucose disposal in maturity-onset diabetes. Table IV and Fig. 9 show the fractional disposal of circulating glucose to $\mathrm{CO}_{2}$, to excretion, and to other fates in the morning and in the evening in the healthy and in the diabetic subjects. Time-related and diabetes-related differences in absolute glucose oxidation rates, and in the fraction of $\mathrm{CO}_{2}$ derived from circulating glucose, were absent or minor (Table IV, rows 3 and 5 ). The diabetes-related drop in the fractional glucose oxidation rate was very large (row 4), because of the much

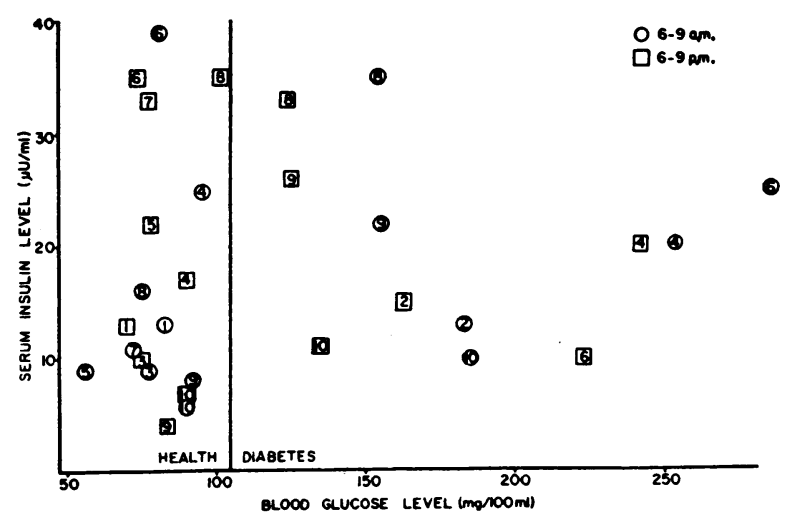

Figure 8 The relationship of the serum insulin level to the fasting blood glucose level in the morning and in the evening in the healthy subjects and in those diabetic subjects who had not previously received insulin injections. 


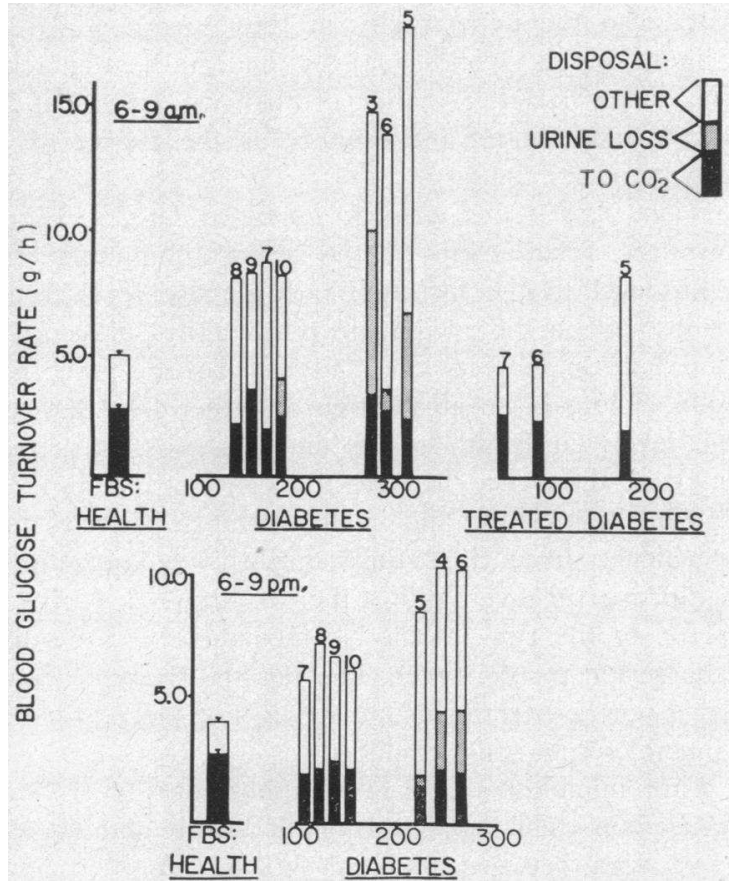

FIgURe 9 The amount of glucose oxidized to $\mathrm{CO}_{2}$ and the amount of glucose excreted in the urine in relation to the total glucose turnover rate in the morning and in the evening in the healthy and in the diabetic subjects. The wider bars on the left indicate the mean \pm SEM of the values obtained in the healthy subjects. The remaining bars indicate the values obtained in the individual diabetic subjects identified by the number (Table II) at the top of the bars. The effect of treatment with depot insulin is shown at the upper right. A principal purpose of the figure is to indicate the large amount of circulating glucose in maturity-onset diabetic subjects that is neither oxidized nor excreted (upper clear portion of the bars), and the metabolic fate of which is presently unknown. FBS, fasting blood glucose level.

higher glucose turnover rate in the diabetic subjects. In health the majority, but in diabetes the minority, of circulating glucose was irreversibly removed from the body by oxidation or excretion (Fig. 9). The principal purpose of Fig. 9 (clear upper bars) is to make the point that the metabolic fate of the excess circulating glucose in maturity-onset diabetes is unknown. Fig. 9 also demonstrates that with conventional depot-insulin treatment, fractional as well as total glucose disposal returns to normal if the fasting blood glucose level is restored to its normal range, but not if the glucose level remains elevated.

\section{DISCUSSION}

Experimental diabetes in insulin-deficient animals is characterized by an increase in hepatic gluconeogenesis $(28,29)$ and glucose output $(30-32)$, and by a decrease in tissue glucose uptake $(32,33)$ and oxidation (31, $33,34)$, with diversion of glucose to renal excretion $(31,32)$. The syndrome is consistent with the action of insulin on the metabolism of glucose in the liver (35) and at the periphery.

The pathophysiology of circulating glucose metabolism in juvenile-onset, insulin-dependent diabetes in man is somewhat less clear. The hepatic glucose output has been reported both as increased $(5,12,36,37)$ and as normal (38). Tissue glucose oxidation is said to be decreased $(1,5,8)$, while tissue glucose uptake has been reported both as increased (12) and as normal (36). These possible differences from experimental insulin deficiency have not been evaluated, but likely are related to severity and to preceding treatment. It is probable that juvenile-onset diabetes in man is the analogue of insulin deficiency in animals.

The literature on the pathophysiology of circulating glucose metabolism in maturity-onset diabetes in man is even more confusing. Most papers report the glucose turnover rate to be normal $(3-10)$. Others, however, report it to be decreased $(1,2)$; and still others report it to be increased $(11,12)$. The glucose oxidation rate likewise has been reported both as normal $(1,5)$ and decreased (8).

The present data indicate that in fasting maturityonset diabetic subjects the glucose turnover rate is increased in proportion to the blood glucose level, with little diversion of glucose to urinary excretion, and that the rate of glucose oxidation is slightly decreased.

\section{Possible reasons for the diversity of findings in} the past

Method. Most studies of glucose turnover in man have been done with a single-injection isotope technic $(1,5,6-14,39-49)$. Despite the view that results obtained by this method are verifiable $(14,50,51)$, it has generally given values for glucose turnover in health from 50 to $150 \%$ higher than those obtained in the present experiments with the primed infusion technic. This discrepancy is consistent with our own comparative findings (Table I). The single-injection technic produces a decay curve that exhibits at least two exponential components (see Methods and 1, 8, 10, 44, $47-49,52,53)$. Unless these components can be resolved (54), this technic tends to overestimate either the glucose pool size or the outflow rate constant (55, $56)$, and therefore the glucose turnover rate. Such errors may in some studies have obscured lower glucose turnover rate found in health, when compared to maturity diabetes.

It must, however, be added that the values for glucose turnover in health in this study also are lower than those found in previous studies in man with the primed 
constant infusion technic $(2,23,57)$. Possible reasons for this are: First, the mean age of our subjects was 57 $\mathrm{yr}$, a circumstance directed by a radiation safety regulation of the Atomic Energy Commission of Canada; the mean subject age in the study of Kreisberg, Pennington, and Boshell (57) was $26 \mathrm{yr}$, while the subject ages in the studies of Kalant, Csorba, and Heller (2) and of Paul and Bortz (23) are not given. Second, special care was taken in this study to maintain basal metabolic conditions. Third, the expression of biologic data as units per unit body weight $(2,57)$ may distort them (58). Fourth, Kalant and associates (2) incorporated an estimate of the glucose pool size into their calculations; it is not clear $(23,57)$ that this adjustment is appropriate to steady-state kinetics.

A range of glucose turnover values similar to that found in the present study does appear in isolated reports both with the single-injection isotope technic (40), and with the hepatic vein catheterization technic (59). Not all of the reasons for the marked discrepancies between the glucose turnover rates found in healthy subjects by various laboratories are readily apparent.

Circadian variation. During the forenoon hours usually assigned to metabolism experiments, the fasting blood glucose level in maturity-onset diabetic subjects is substantially declining (Fig. $1 ; 5,19$ ). This decline results from a profound circadian variation in the circulating glucose inflow rate (Fig. 4, Table III). The average decrease in the glucose inflow rate by evening compared to the morning was $30 \%$ (range $10-53 \%$ ). This value is exclusive of a possible change in the inflow of recycled glucose not measured by the uniformly labeled isotope. It may have been somewhat influenced by, but is not attributable to (Fig. 1, 19), the normal circadian diet pattern (see Methods). It is not surprising that the literature about circulating glucose metabolism in maturity-onset diabetes is confusing, when a circadian pattern of this magnitude has remained previously unrecognized. This pattern has the effect of diminishing the difference between healthy and diabetic subjects as the day goes on, and making steadystate analysis of daytime glucose-tracer experiments hazardous in diabetes.

Circulating glucose metabolism in maturity-onset diabetes in man

Increased glucose inflow rate. The glucose inflow rate increases proportionately to the fasting blood glucose level. This relationship is an extension of that present in health (Figs. 3 and 4 ), and is consistent with that observed in sheep (60). It is such that during the early morning, at a blood glucose level of $300 \mathrm{mg} /$ $100 \mathrm{ml}$, the glucose inflow rate is approximately three to four times normal; during the evening the increment is about one-half as great. The present data are similar in nature to those of Forbath and Hetenyi (12) despite the difference in methodology.

Increased glucose outflow rate. The glucose outflow rate (tissue glucose uptake) also is increased, in a manner qualitatively similar to that of the glucose inflow rate (Fig. 5). This finding follows from the relatively stable blood glucose level at the times of these studies, and from the small urinary glucose loss. It is not presently clear whether in this respect maturity-onset diabetes differs qualitatively, or only quantitatively, from juvenile-onset diabetes and from experimental insulin deficiency.

Decreased glucose outflow rate constant. The value of $k$ is diminished proportionately to the increase in the fasting blood glucose level (Fig. 6). The relationship is such that during the early morning at a blood glucose level of $300 \mathrm{mg} / 100 \mathrm{ml}$, the mean $k$ value is $38 \%$ less than in health. Thus, the increased glucose outflow rate in diabetes occurs despite an increased resistance to glucose removal, as a result of the rise in the blood glucose concentration.

Contribution to hyperglycemia of glucose overproduction and underutilization. For the maturity-diabetic group, although not for each individual, it was possible to calculate the relative contribution to hyperglycemia of the increased glucose inflow rate and of the decreased glucose outflow rate constant, and to this extent resolve the question of the roles of glucose overproduction and underutilization (Fig. 7c). Overproduction appears to be the greater factor and the role of underutilization to increase with severity.

Rate concentration relationships. The reason for the absence of evidence of saturability (61) of glucose removal in the rate concentration relationship in the diabetic subjects (absence of plateauing in Fig. 5) is not clear. This absence is not an artifact of the primed infusion technic (62), but may result from the limited number of subjects and data range.

Circadian variability. The marked circadian variation of the glucose inflow rate in the diabetic subjects (Fig. 4, Table III) is an exaggeration of the qualitatively similar variation in the healthy subjects (Fig. 3 ). These changes are consistent with circadian fluctuations in hepatic glycogen content in animal species (63). Their cause is unknown. They are in rather than out of phase with the higher insulin level found in the morning in other studies (64-68), although not in this one, suggesting that such changes in insulin level may be a response to, rather than a cause of, the change in hepatic glucose output. The possibility of primary changes in the portal insulin level has not been investigated. There were no cyclic changes in growth hormone levels in this study or in previous studies of 
the relevant time periods $(69,70)$. The alteration in hepatic glucose formation is consistent in phase with the serum cortisol cycle, but is said to survive, at least in part, adrenalectomy and hypophysectomy (63). It may be light-mediated (71). It may reflect multifactorial variation in hepatic gluconeogenetic enzymes (72-74) coordinated with respect to time in some unknown way by the hypothalamus (74).

The lessened $k$ value for glucose outflow during the evening in comparison to the morning is probably related in part to the lower serum insulin level said to prevail at that time (64-66), which may in turn result from the decrease in the glucose inflow rate. However, insulin sensitivity is also said to be diminished in the evening (75). The lower outflow rate constant is consistent with the lessening of glucose tolerance in the afternoon as compared to the morning $(68,76-78)$.

Response of glucose turnover rate to insulin therapy. When the fasting blood glucose level in the diabetic subjects was lowered by treatment with depot insulin, the glucose turnover rate also correspondingly diminished, in accordance with the rate concentration relationship established by the data from the untreated diabetic and healthy subjects (Fig. 4). Similarly, the glucose outflow rate constant rose (Fig. 6). Thus, as it is used pharmacologically in conventional diabetes management, depot insulin is capable of restoring not only a normal fasting blood glucose level, but also a normal glucose inflow rate, and a normal balance between glucose inflow and the resistance to glucose outflow. The alternative possibility, that the pharmacologic use of insulin might have lowered the blood glucose level by disproportionately augmenting glucose outflow, and thus allowing the increased glucose turnover rate to continue, did not occur. In this sense, then, conventional treatment with depot insulin constitutes physiologic replacement in the fasting state.

However, the fact that the increased glucose flux in maturity-onset diabetes can be corrected by the pharmacologic use of exogenous insulin does not necessarily imply that this increase is caused primarily by insulin lack. The present studies do not provide evidence that this is so. In particular, the large circadian changes in glucose flux appear to be independent at least of changes in the peripheral serum insulin levels. A multifactorial interaction between a primary disorder of gluconeogenesis (79), impaired beta-cell insulin reserve, and other intersubject variables (80) that relate to the occurrence of diabetes within members of a population seems more probable.

Relationship of glucose oxidation to glucose turnover. In healthy subjects, $64 \%$ of circulating glucose appeared as expired $\mathrm{CO}_{2}$, and $21 \%$ of $\mathrm{CO}_{2}$ was derived from circulating glucose. With isolated exceptions (23,
$31,57)$, these fractions are in general agreement with the corresponding values in the literature for man (1, $5,8,15,41,45,46,48,81)$ and for animals (33, 34, 82-84). Nevertheless, they are probably substantial underestimates. It has been pointed out that isotopic equilibration within the bicarbonate pool in man (22, 23 ), in contrast to that of small laboratory animals with rapid metabolic rates (85), is not complete even after several hours. Paul and Bortz (23) found an average values of $37 \%$ of expired $\mathrm{CO}_{2}$ derived from circulating glucose in postabsorptive subjects; because of their higher values for glucose turnover, the fraction of circulating glucose appearing as $\mathrm{CO}_{2}$ was the same as in the present study. The problem is in need of further clarification. It relates to the possibility that glucose may not be the only source of cerebral $\mathrm{CO}$ production $(86,87)$ even early in the postabsorptive state.

While doubt is thus cast upon the absolute values for glucose oxidation, there seems no reason to think that bicarbonate kinetics would differ in health and diabetes (5). Accordingly, the underestimates are probably similar in the two groups of subjects, and the data would appear to be valid for comparative purposes.

The results of previous comparisons of the glucose oxidation rate in maturity-onset diabetes and in health have been variable $(1,5,8)$. In this study the rate was slightly decreased in diabetes (Table IV). In juvenile-onset diabetes in man $(1,8)$, and in experimental diabetes in animals $(31,33,34)$, the rate of glucose oxidation has been consistently decreased.

The present study provides a different perspective of the glucose oxidation rate in maturity-onset diabetes than do previous studies, because of the demonstration that the glucose turnover rate is markedly increased. Thus, while it may be true that the absolute rate of disposal of circulating glucose to $\mathrm{CO}_{2}$ is only marginally reduced in this form of diabetes, the fraction of the circulating glucose appearing as $\mathrm{CO}_{2}$ becomes markedly diminished as the blood glucose level rises (Fig. 9, Table IV). In the healthy subjects only 30$40 \%$, or $1-2 \mathrm{~g} / \mathrm{h}$, of endogenously formed glucose was not irreversibly removed from the body as expired $\mathrm{CO}_{2}$; the glucose oxidation rate having been underestimated (see above), this fraction is, in fact, even less. In the subjects with severe maturity-onset diabetes, up to $70-80 \%$, or $10-12 \mathrm{~g} / \mathrm{h}$, was neither oxidized nor excreted, and even though glucose oxidation has been underestimated, this unrecovered fraction is clearly very much larger in health. It undergoes some unknown internal disposal. Doubtless the absolute amounts would vary with the duration of fasting, which in this protocol was relatively short. Nevertheless it is clear that in the untreated or inadequately treated maturity-onset 
diabetic subject there is in the postabsorptive state an internal flux of excess glucose from unknown precursors into unknown tissues and unknown metabolic fates.

\section{A general implication of the present findings}

The marked increase in the endogenous glucose turnover rate in untreated maturity-onset diabetes demonstrated in these studies, and its suppression by insulin treatment, give a more palpable image to the disorder of circulating glucose metabolism in this diabetic state than that conveyed by the conventional, unidimensional, fasting blood glucose level. The glucose level is only the still silhouette of a greatly hypertrophied endogenous glucose flux. There is no way of knowing at present whether this excess glucose flux is harmful. However, those who assume that control of the blood glucose level in diabetes is not a useful therapeutic objective might reflect upon it. Neither its origin nor its fate are known. It is available, at least, for incorporation on the short term into circulating lipids (88), and on the long term into interstitial glycoproteins $(89,90)$. It could serve as a significant contributor to the eventual demise of the diabetic patient.

\section{APPENDIX}

The amount of the priming dose for the constant [U-C ${ }^{14}$ ] glucose infusions was calculated as follows: $y+x t=10$, where $y=$ the priming dose in $\mu \mathrm{Ci}, x=$ the infusion rate in $\mu \mathrm{Ci} / \mathrm{h}, t=$ the duration of the infusion in hours and $10=$ the total dose (injected plus infused) of the radioisotope in $\mu \mathrm{Ci}$. Sp act eq $=y / p$, where sp act eq $=$ equilibrium specific activity, and $p=$ the approximate glucose pool size (blood glucose level in $g$ /liter $\times 20$ liters). Sp act eq $=x / T$, where $T$ $=$ the approximate expected glucose turnover rate in $\mathrm{g} / \mathrm{h}$. Then

$$
\frac{y}{p}=\frac{x}{T}, x=\frac{y T}{p}, y+\frac{y T t}{p}=10, \text { and } y=\frac{10}{1+\frac{t T}{p}} .
$$

\section{ACKNOWLEDGMENTS}

This work was supported by Operating Grant MT811 from the Medical Research Council of Canada.

\section{REFERENCES}

1. Reichard, G. A., Jr., A. G. Jacobs, P. Kimbel, N. J. Hochella, and S. Weinhouse. 1961. Blood glucose replacement rates in normal and diabetic humans. $J$. Appl. Physiol. 16: 789.

2. Kalant, N., T. R. Csorba, and N. Heller. 1963. Effect of insulin on glucose production and utilization in diabetes. Metab. (Clin. Exp.). 12: 1100

3. Myers, J. D. 1950. Net splanchnic glucose production in normal man and in various disease states. J. Clin. Invest. $29: 1421$.

4. Bearn, A. G., B. H. Billing, and S. Sherlock. 1951. Hepatic glucose output and hepatic insulin sensitivity in diabetes mellitus. Lancet. 2: 698 .
5. Shreeve, W. W., N. Baker, M. Miller, R. A. Shipley, G. E. Incefy, and J. W. Craig. 1956. $\mathrm{C}^{14}$ studies in carbohydrate metabolism. II. The oxidation of glucose in diabetic human subjects. Metab. (Clin. Exp.). 5: 22.

6. Searle, G. L., G. E. Mortimore, R. E. Buckley, and W. A. Reilly. 1959. Plasma glucose turnover in humans as studied with $\mathrm{C}^{14}$ glucose. Influence of insulin and tolbutamide. Diabctes. 8: 167.

7. Reichard, G. A., N. F. Moury, Jr., N. J. Hochella, A. L. Patterson, and S. Weinhouse. 1963. Quantitative estimation of the Cori cycle in the human. J. Biol. Chem. 238: 495 .

8. Manougian, E., M. Pollycove, J. A. Linfoot, and J. H. Lawrence. 1964. $\mathrm{C}^{\mathbf{1 4}}$ glucose kinetic studies in normal, diabetic, and acromegalic subjects. J. Nucl. Med. 5: 763.

9. Brech, W. J., J. A. Glennon, and E. S. Gordon. 1970. Kinetische Untersuchungen des Glucosestoffwechsels. II. Glucosepool, Glucoseumsatz and Cori-Cyclus bei Adipositas. Klin. Wochensch. 48: 529.

10. Reaven, G. M., A. Silvers, and J. W. Farquhar. 1970. Study of the relationship between plasma insulin concentration and efficiency of glucose uptake in normal and mildly diabetic subjects. Diabetes. 19: 571 .

11. Jacobs, G., G. Reichard, E. H. Goodman, Jr., B. Friedmann, and S. Weinhouse. 1958. Action of insulin and tolbutamide on blood glucose entry and removal. $D i$ abetes. $7: 358$.

12. Forbath, N., and G. Hetenyi, Jr. 1966. Glucose dynamics in normal subjects and diabetic patients before and after a glucose load. Diabetes. 15: 778.

13. De Meutter, R. C., and W. W. Shreeve. 1963. Conversion of DL-Lactate-2-C $C^{14}$ or $-3-C^{14}$ or pyruvate-2-C $\mathrm{C}^{14}$ to blood glucose in humans: effects of diabetes, insulin, tolbutamide, and glucose load. J. Clin. Invest. 42: 525

14. Forbath, N., A. B. Kenshole, and G. Hetenyi, Jr. 1967. Turnover of lactic acid in normal and diabetic dogs calculated by two tracer methods. Am. J. Physiol. 212: 1179.

15. Baker, N., W. W. Shreeve, R. A. Shipley, G. E. Incefy, and M. Miller. 1954. C $^{\mathbf{1 4}}$ studies in carbohydrate metabolism. I. The oxidation of glucose in normal human subjects. J. Biol. Chem. 211: 575.

16. Wrenshall, G. A., G. Hetenyi, Jr., and C. H. Best. 1961. The validity of rates of glucose appearance in the dog calculated by the method of successive tracer injections. II. The influence of intermixing time following tracer injection. Can. J. Biochem. Physiol. 39: 267.

17. Searle, G. L., E. H. Strisower, and I. L. Chaikoff 1954. Glucose pool and glucose space in the normal and diabetic dog. Am. J. Physiol. 176: 190.

18. Steele, R., J. S. Wall, R. C. de Bodo, and N. Altszuler. 1956. Measurement of size and turnover rate of body glucose pool by the isotope dilution method. Am. J. Physiol. $187: 15$.

19. Faiman, C., and J. A. Moorhouse. 1967. Diurnal variation in the levels of glucose and related substances in healthy and diabetic subjects during starvation. Clin. Sci. (Oxf.). 32: 111

20. Robinson, R. J., and R. V. Coxon. 1957. Radioactivity of blood carbon dioxide in animals oxidizing glucose labelled with carbon-14 and other labelled substances. Nature (Lond.). 180: 1279.

21. Coxon, R. V., and R. J. Robinson. 1959. Movements of radioactive carbon dioxide within the animal body dur- 
ing oxidation of ${ }^{14} \mathrm{C}$-labelled substances. J. Physiol. (Lond.). $147: 487$

22. Issekutz, B., Jr., P. Paul, H. I. Miller, and W. M. Bortz. 1968. Oxidation of plasma FFA in lean and obese humans. Metab. (Clin. Exp.). 17: 62.

23. Paul, P., and W. M. Bortz. 1969. Turnover and oxidation of plasma glucose in lean and obese humans. $\mathrm{Me}$ tab. (Clin. Exp.). 18: 570.

24. Blair, A., and S. Segal. 1960. The isolation of blood glucose as potassium gluconate. J. Lab. Clin. Med. 55: 959.

25. Long, C. L., and J. W. Geiger. 1965. Liquid scintillation counting of the potassium gluconate derivative of blood glucose. Anal. Biochem. 10: 253.

26. Fredrickson, D. S., and K. Ono. 1958. An improved technique for assay of $\mathrm{C}^{14} \mathrm{O}_{2}$ in expired air using the liquid scintillation counter. J. Lab. Clin. Med. 51:147.

27. Morgan, C. R., and A. Lazarow. 1963. Immunoassay of insulin; two antibody system. Plasma insulin levels of normal, subdiabetic and diabetic rats. Diabetes. 12:115.

28. Renold, A. E., C. T. Teng, F. B. Nesbett, and A. B. Hastings. 1953. Studies of carbohydrate metabolism in rat liver slices. II. The effect of fasting and of hormonal deficiencies. J. Biol. Chem. 204: 533.

29. Exton, J. H., L. S. Jeffereson, Jr., R. W. Butcher, and C. R. Park. 1966. Gluconeogenesis in the perfused liver. The effects of fasting, alloxan diabetes, glucagon, epinephrine, adenosine $3^{\prime}, 5^{\prime}$-monophosphate, and insulin. Am. J. Med. 40: 709.

30. Stetten, D., Jr., I. D. Welt, D. J. Ingle, and E. H. Morley. 1951. Rates of glucose production and oxidation in normal and diabetic rats. J. Biol. Chem. 192: 817.

31. Feller, D. D., I. L. Chaikoff, E. H. Strisower, and G. L. Searle. 1951. Glucose utilization in the diabetic dog studied with $\mathrm{C}^{14}$-glucose. J. Biol. Chem. 188: 865.

32. Wrenshal, G. A., A. M. Rappaport, C. H. Best. J. S. Cowan, and G. Hetenyi, Jr. 1964. Absolute rates of glucose production, accumulation and utilization in the dog at pancreatectomy and thereafter. Diabetes. 13: 500.

33. Shipley, R. A., E. B. Chudzik, and A. P. Gibbons. 1970. Rate of disposal of glucose carbon to $\mathrm{CO}_{2}$, fat, protein, and glycogen in the diabetic rat. Am. J. Physiol. 219 : 364.

34. Searle, G. L., E. H. Strisower, and I. L. Chaikoff. 1956. Determination of rates of glucose oxidation in normal and diabetic dogs by a technique involving continuous injection of $\mathrm{C}^{14}$-glucose. Am. J. Physiol. 185: 589.

35. Madison, L. L. 1969. Role of insulin in the hepatic handling of glucose. Arch. Intern. Med. 123: 284.

36. Bondy, P. K., W. L. Bloom, V. S. Whitner, and B. W. Farrar. 1949. Studies of the role of the liver in human carbohydrate metabolism by the venous catheter technic II. Patients with diabetic ketosis, before and after the administration of insulin. J. Clin. Invest. 28: 1126.

37. Martin, F. I. R., and M. J. Pearson. 1971. Acute hypoglycemic action of insulin in insulin-dependent diabetics. Metab. (Clin. Exp.). 20: 859 .

38. Wahren, J., P. Felig, E. Cerasi, and R. Luft. 1972. Splanchnic and peripheral glucose and amino acid metabolism in diabetes mellitus. J. Clin. Invest. 51: 1870.

39. Franckson, J. R. M., W. Malaise, Y. Arnould, E Rasio, H. A. Ooms, E. Balasse, V. Conrad, and P. A.
Bastenie. 1966. Glucose kinetics in human obesity. Diabetologia. 2: 96

40. Searle, G. L., S. Schilling, D. Porte, J. Barbaccia, J. De Grazia, and R. R. Cavalieri. 1966. Body glucose kinetics in nondiabetic human subjects afer phenethylbiguanide. Diabctes. 15 : 173.

41. Waterhouse, C., and J. H. Kemperman. 1966. Changes in oxidative metabolism with glucose ingestion. J. Lab. Clin. Med. $68: 250$.

42. Cahill, G. F., Jr., M. G. Herrera, A. P. Morgan, J. S Soeldner, J. Steinke, P. L. Levy, G. A. Reichard, Jr., and D. M. Kipnis. 1966. Hormone-fuel interrelationships during fasting. J. Clin. Invest. 45: 1751.

43. Rabinowitz, J. L., and R. M. Myerson. 1967. The effects of triiodothyronine on some metabolic parameters of obese individuals. Blood $\mathrm{C}^{14}$-glucose replacement rate, respiratory $\mathrm{C}^{14} \mathrm{O}_{2}$, the pentose cycle, the biological half-life of $\mathrm{T}_{3}$ and the concentration of $\mathrm{T}_{3}$ in adipose tissue. Metab. (Clin. Exp.). 16: 68.

44. Young, D. R., R. Pelligra, J. Shapira, R. R. Adachi, and K. Skrettingland. 1967. Glucose oxidation and replacement during prolonged exercise in man. J. Appl. Phyisol. $23: 734$.

45. Kreisberg, R. A. 1968. Glucose metabolism in normal and obese subjects. Effect of phenformin. Diabetes. 17 : 481.

46. Searle, G. L., R. Gulli, and R. R. Cavalieri. 1969. Effect of phenformin in nondiabetic humans. Estimation of glucose turnover rate and Cori Cycle activity. Metab. (Clin. Exp.). 18: 148.

47. Waterhouse, C., and J. Keilson. 1969. Cori cycle activity in man. J. Clin. Invest. 48: 2359.

48. Long, C. L., J. L. Spencer, J. M. Kinney, and J. W. Geiger. 1971. Carbohydrate metabolism in normal man and effect of glucose infusion. J. Appl. Phy'siol. $31: 102$.

49. Shames, D. M., M. Berman, and S. Segal. 1971. Effects of thyroid disease on glucose oxidative metabolism in man. A compartmental model analysis. J. Clin. Invest. 50: 627 .

50. Hetenyi, G., Jr., R. Ninomiya, and G. A. Wrenshall. 1966. Glucose production rates in dogs determined by two different tracers and tracer methods. J. Nucl. Med. $7: 454$.

51. Cowan, J. S., D. Schachter, and G. Hetenyi, Jr. 1969. Validity of a tracer-injection method for studying glucose turnover in normal dogs. J. Nucl. Med. 10:98.

52. Reichard, G. A. Jr., A. G. Jacobs, B. Friedmann, P. R. Kimbel, N. J. Hochella, and S. Weinhouse. 1959. Effects of insulin and tolbutamide on production and utilization of blood sugar. Metab. (Clin. Exp.). 8: 486.

53. Baker, N., R. A. Shipley, R. E. Clark, and G. E. Incefy. 1959. $\mathrm{C}^{14}$ Studies in carbohydrate metabolism: glucose pool size and rate of turnover in the normal rat. Am. J. Physiol. 196: 245.

54. Searle, G. L., and R. R. Cavalieri. 1972. Determination of lactate kinetics in the human analysis of data from single injection vs. continuous infusion methods. Proc. Soc. Exp. Biol. Med. 139: 1002

55. Steele, R. 1964. Reflection on pools. Fed. Proc. 23 : 671.

56. Steele, R. 1966. The influences of insulin on the hepatic metabolism of glucose. Rev. Physiol. Biochem. Exp. Pharmacol. 57: 91 .

57. Kreisberg, R. A., L. F. Pennington, and B. R. Boshell. 1970. Lactate turnover and gluconeogenesis in normal and obese humans. Effect of starvation. Diabetes. 19 : 53 . 
58. daCosta, F., and J. A. Moorhouse. 1969. Protein nutrition in aged individuals on self-selected diets. $\mathrm{Am}$. J. Clin. Nutr. 22: 1618.

59. Kibler, R. F., W. J. Taylor, and J. D. Myers. 1964. The effect of glucagon on net splanchnic balances of glucose, amino acid nitrogen, urea, ketones, and oxygen in man. J. Clin. Invest. 43: 904.

60. Bergman, E. N. 1964. Glucose turnover rates in pregnant and nonpregnant sheep. Nature (Lond.). 202: 1333.

61. Moorhouse, J. A., C. S. Smithen, and E. S. Houston. 1967. A study of glucose transport kinetics in man by means of continuous glucose infusions. J. Clin. Endocrinol. Metab. $27: 256$.

62. Issekutz, B., Jr., and M. Allen. 1972. Effect of catecholamines and methylprednisolone on carbohydrate metabolism of dogs. Metab. (Clin. Exp.). 21: 48.

63. Sollberger, A. 1964. The control of circadian glycogen rhythms. Ann. N. Y. Acad. Sci. 117: 519.

64. Freinkel, N., M. Mager, and L. Vinnick. 1968. Cyclicity in the interrelationships between plasma insulin and glucose during starvation in normal young men. J. Lab. Clin. Med. $71: 171$.

65. Malherbe, C., M. de Gasparo, R. de Hertogh, and J. J. Hoet. 1969. Circadian variations of blood sugar and plasma insulin levels in man. Diabetologia. $5: 397$.

66. Hadden, D. R., S. K. Bhatia, A. Rigas, J. A. Weaver, and D. A. D. Montgomery. Circadian variation of glucose, insulin and free fatty acids during the long-term use of oral hypoglycaemic agents in diabetes mellitus with special reference to glibenclamide. Postgrad. Med. $J$. 46 (Dec. Suppl.) : 53.

67. Gagliardino, J. J., and R. E. Hernandez. 1971. Circadian variation of the serum glucose and immunoreactive insulin levels. Endocrinology. 88: 1529.

68. Jarrett, R. J., I. A. Baker, H. Keen, and N. W. Oakley. 1972. Diurnal variation in oral glucose tolerance; blood sugar and plasma insulin levels morning, afternoon and evening. Br. Med. J. 1: 199.

69. Nakagawa, K. 1971. Probable sleep dependency of diurnal rhythm of plasma growth hormone response to hypoglycemia. J. Clin. Endocrinol. Metab. 33: 854 .

70. Hansen, A. P., and K. Johansen. 1970. Diurnal patterns of blood glucose, serum free fatty acids, insulin, glucagon, and growth hormone in normals and juvenile diabetics. Diabetologia. $6: 27$.

71. Pauly, J. E., and L. E. Scheving. 1967. Circadian rhythms in blood glucose and the effect of different lighting schedules, hypophysectomy, adrenal medullectomy and starvation. Am. J. Anat. 120: 627 .

72. Phillips, L. J., and L. J. Berry. 1970. Circadian rhythm of mouse liver phosphoenolypyruvate carboxykinase. Am. J. Physiol. 218: 1440.

73. Phillips, L. J., and L. J. Berry. 1970. Hormonal control of mouse liver phosphoenolpyruvate carboxykinase rhythm. Am. J. Phy'siol. 219: 697.

74. Black, I. B., and D. J. Reis. 1971. Central neural regulation by adrenergic nerves of the daily rhythm in hepatic tyrosine transaminase activity. J. Physiol. (Lond.). 219: 267.

75. Gibson, T., and R. J. Jarrett. 1972. Diurnal variation in insulin sensitivity. Lancet. 2: 947.

76. Roberts, H. J. 1964. Afternoon glucose tolerance testing: a key to the pathogenesis, early diagnosis and prognosis of diabetogenic hyperinsulinism. J. Am. Geriatr. Soc. 12: 423.

77. Bowen, A. J., and R. L. Reeves. 1967. Diurnal variation in glucose tolerance. Arch. Intern. Med. 119: 261

78. Ben-Dyke, R. 1971. Diurnal variation of oral glucose tolerance in volunteers and laboratory animals. Diabetologia. $7: 156$.

79. Seidman, I., A. A. Horland, and G. W. Teebor. 1967. Hepatic glycolytic and gluconeogenic enzymes of the obese-hyperglycemic mouse. Biochim. Biophys. Acta. 146: 600 .

80. Unger, R. H. 1971. Glucagon and the insulin: glucagon ratio in diabetes and other catabolic illnesses. Diabetes. 20: 834 .

81. Brech, W. J., J. A. Glennon, and E. S. Gordon. 1970. Kinetische Untersuchungen des Glucosestoff wechsels. I. Glucosepool, Glucoseumsatz, and Cori-cyclus bei normalen Versuchspersonen. Klin. Wochenschr. 48: 521.

82. Steele, R., N. Altszuler, J. S. Wall, A. Dunn, and R. C. de Bodo. 1959. Influence of adrenalectomy on glucose turnover and conversion to $\mathrm{CO}_{2}$ : studies with $\mathrm{C}^{14}$ glucose in the dog. Am. J. Physiol. 196: 221.

83. Shipley, R. A., E. B. Chudzik, A. P. Gibbons, K. Jongedyk, and D. O. Brummond. 1967. Rate of glucose transformation in the rat by whole-body analysis after glucose ${ }^{14} \mathrm{C}$. Am. J. Physiol. 213: 1149.

84. Steele, R., B. Winkler, I. Rathgeb, C. Bjerknes, and N. Altszuler. 1968. Plasma glucose and free fatty acid metabolism in normal and long-fasted dogs. Am. J. Physiol. 214: 313 .

85. Morris, B., and M. W. Simpson-Morgan. 1963. The excretion of ${ }^{14} \mathrm{CO}_{2}$ during the continuous intravenous infusion of $\mathrm{NaH}^{14} \mathrm{CO}_{3}$ in unanaesthetized rats. J. Physiol. (Lond.). 169: 713

86. Sacks, W. 1957. Cerebral metabolism of isotopic glucose in normal human subjects. J. Appl. Physiol. 10: 37.

87. Owen, O. E., A. P. Morgan, H. G. Kemp, J. M. Sullivan, M. G. Herrera, and G. F. Cahill, Jr. 1967. Brain metabolism during fasting. J. Clin. Invest. 46: 1589.

88. Barter, P. J., P. J. Nestel, and K. F. Carroll. 1972. Precursors of plasma triglyceride fatty acid in humans. Effects of glucose consumption, clofibrate administration, and alcoholic fatty liver. Metab. (Clin. Exp.). $21: 117$.

89. Beisswenger, P. J., and R. G. Spiro. 1970. Human glomerular basement membrane: chemical alteration in diabetes mellitus. Science (Wash. D. C.). 168: 596.

90. Spiro, R. G., and M. J. Spiro. 1971. Effect of diabetes on the biosynthesis of the renal glomerular basement membrane. Studies on glucosyltransferase. Diabetes. 20: 641. 